\title{
Marie Rennotte, pedagoga e médica: subsídios para um estudo histórico-biográfico e médico-social
}

\author{
Marie Rennotte, educator and \\ medical doctor: elements for a \\ bistorical and biographical, social \\ and medical study
}

Leonora De Luca

Mestre em sociologia e doutoranda em ciências sociais do Instituto de Filosofia e Ciências Humanas da Universidade Estadual de Campinas (Unicamp) assisdeluca@directnet.com.br

João Bosco Assis De Luca

Médico pela Faculdade de Ciências Médicas da Universidade Estadual de Campinas (Unicamp) assisdeluca@directnet.com.br

PALAVRAS-CHAVE: Marie Rennotte, sesquicentenário, história da medicina, história do pensamento.

At the time of Marie Rennotte's $150^{\text {th }}$ birthday celebrations, a new focus on her meaningful actions as a Belgian-Brazilian pioneer professional in Education and Science in São Paulo at the turn of the $19^{\text {th }}$ to the $2 O^{\text {h }}$ centuries begins to take place. The present paper is a preliminary chronological draft with bibliography and recommended documents that will allow researchers from different areas to develop deeper historic, biographical, medical and social studies demanded by Rennotte's extraordinary personal dimensions and the unusual scope of her actions in São Paulo society.

KEYWORDS: Marie Rennotte, sesquicentennial, history of medical science, history of mentality. 


\section{Introdução}

Cabelos loiros, olhos cinzentos, nariz reto, boca mediana, queixo redondo, 160 centímetros de estatura: a descrição padronizada que constava do passaporte concedido a mademoiselle Marie Rennotte pelo consulado belga do Rio de Janeiro, em junho de 1885, pouco diferiria daquela registrada pelos documentos das muitas outras professorinhas européias que ainda aportavam na capital brasileira no final do Império à procura de trabalho depois de uma penosa viagem que implicava, na prática, a troca da dura realidade vigente em seu tumultuado e superpovoado Velho Mundo de origem pelos sonhos de auto-realização em uma jovem e promissora América.

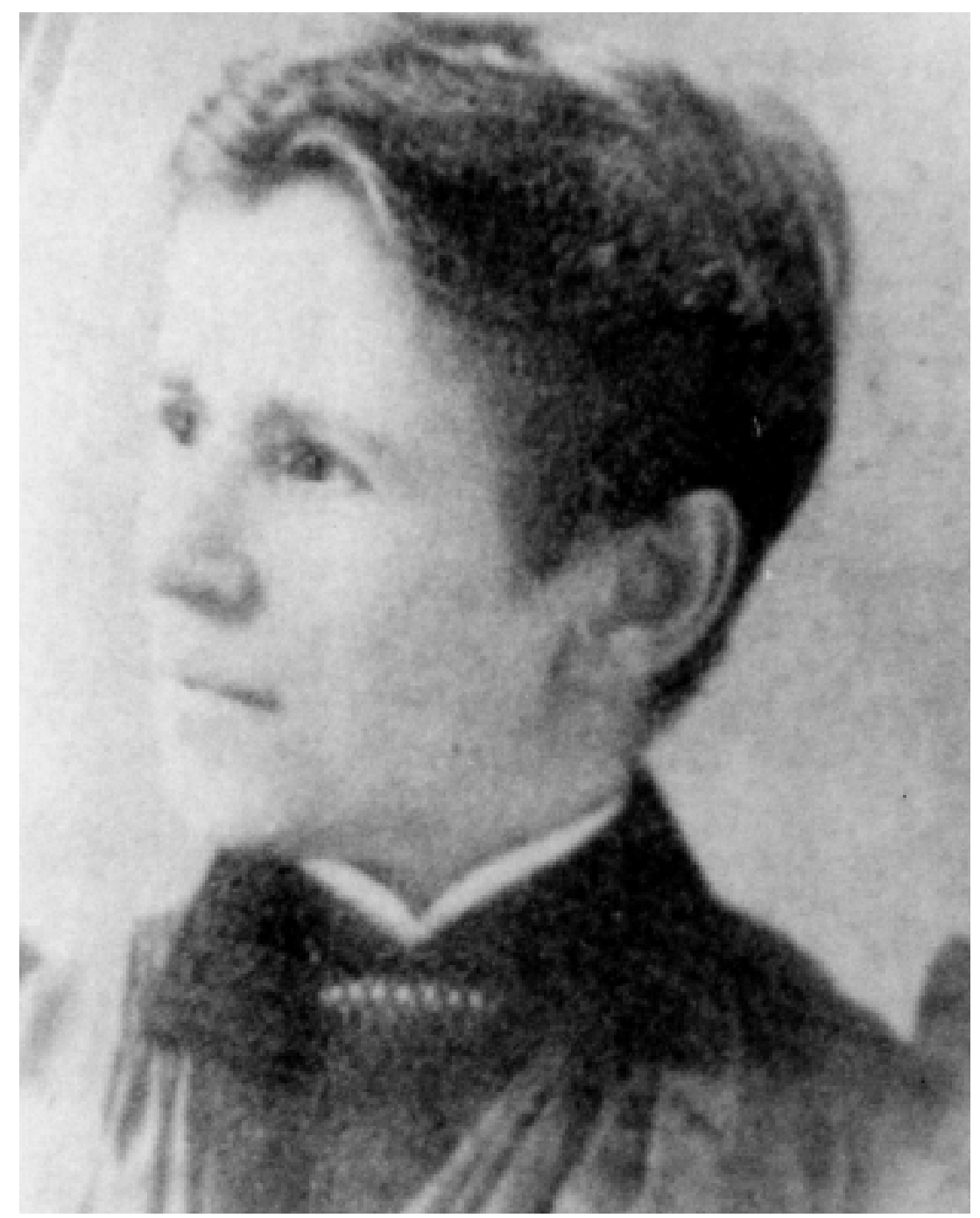

Maria Rennotte provavelmente em sua colação de grau como médica, em 1892. 
O que distingue essa moça de tantas outras, no entanto, é o singular percurso de sua vida nesse processo de auto-realização. Ao contrário da imensa maioria de suas colegas imigrantes, cujos nomes caíram no esquecimento, Marie Rennotte deixaria marcas profundas na São Paulo da virada do século XIX para o XX: depois de atuar como revolucionária pedagoga no interior da então província paulista dos anos 1880, iria graduar-se em medicina, instalando-se na capital paulista a partir de 1895 como obstetra e ginecologista, tornando-se pioneira entre as mulheres no exercício local da profissão médica. Em uma época em que a incipiente saúde pública limitava-se à preocupação mais imediata com o saneamento urbano, e em que a prática da medicina raramente excedia o plano da intervenção personalista nas camadas mais privilegiadas da sociedade, ela perseguia objetivos mais essenciais, inspirados nos valores libertários que haviam regido sua atuação como pedagoga.

A história dessa mulher incomum, cujo sesquicentenário de nascimento se comemorou em 2002, começa a ser resgatada, existindo ainda muito por ser esclarecido, tanto a respeito de sua vida como do complexo contexto social em que atuou - tarefa árdua que exigiria investigações em diferentes países e a observação de fontes impressas ou manuscritas que tendem a desaparecer com rapidez.

O presente trabalho, de dimensões modestas, tem, portanto, o duplo objetivo de assinalar a efeméride do sesquicentenário de Marie Rennotte e de fornecer os dados já disponíveis a seu respeito para os pesquisadores que venham a se interessar pelo esclarecimento do muito que sobre ela ainda permanece na obscuridade. Ordenamos os dados num perfil cronológico abrangente, alicerçado nas imprescindíveis indicações bibliográficas e documentais.

\section{Cronologia}

1852

Filha de pais belgas, Jeanne-Françoise-Joséphine-Marie Rennotte nasce em 11 de fevereiro (data que consta do Brevet de Capacité pour l'Enseignement Primaire, concedido em 1875), na Bélgica, em Wandre, pequena comuna fornecedora de carvão-de-pedra para as indústrias metalúrgicas da Wallonie, situada nos arredores de Liège.

1874

Aos 22 anos recebe seu certificado de conclusão do curso normal. No documento, datado de 19 de julho, são destacados seus desempenhos no domínio musical e nas línguas francesa e alemã (Société pour l'Instruction Élémentaire, Paris).

1875

Após exames realizados em Paris, é considerada apta para a obtenção, em 20 de julho, do Brevet de Capacité pour l'Enseignement Primaire, concedido em caráter oficial pela recém-constituída República francesa. 
1878

Aos 26 anos, chega ao Brasil, em maio de 1878 (1879, segundo Ana Maria de Revoredo, mencionada adiante). Aportou no Rio de Janeiro, onde teria permanecido até 1882, desempenhando a função de preceptora ou lecionando em colégios particulares.

1880

Morre no Rio de Janeiro, em 20 de maio, Ana Néri (1814-80), precursora da enfermagem científica no Brasil, voluntária de excepcional atuação no front da guerra do Paraguai (1864-70). Como sua morte ocorreu poucos meses depois do falecimento do general Osório e poucos dias depois da morte do duque de Caxias, o sepultamento, no dia seguinte, se dá em meio a extraordinárias solenidades, sendo provável que Rennotte fizesse parte do cortejo que acompanhou os despojos de Ana Néri até o cemitério.

1882

Contratada pelo Colégio Piracicabano, inovador internato feminino inaugurado em 13 de setembro de 1881 pela missionária metodista norte-americana Martha Watts, na florescente cidade de Piracicaba (SP). Rennotte assume a responsabilidade pela orientação educacional da escola e pelo ensino de ciências naturais, ministrado com metodologia revolucionária para a época. Adota referenciais intuicionistas, cientificistas, positivistas e evolucionistas que vinculam sua pedagogia a Rousseau, Pestalozzi, Froebel, Comte e Spencer. Conta com o apoio das facções mais progressistas da região (liberais, republicanas, maçônicas e abolicionistas), em especial dos influentes irmãos ituanos Morais Barros (Manuel e Prudente, futuro presidente da República), então radicados naquela cidade.

1883

O sucesso do Colégio Piracicabano provoca a reação das facções antiliberais e ultramontanas do interior da província de São Paulo. Preteridas na captação de novas alunas, as irmãs de São José, mantenedoras do Colégio de Nossa Senhora do Patrocínio (da vizinha cidade de Itu), promovem uma campanha de difamação contra as professoras da nova escola. Em defesa da instituição à qual pertence, a professora Rennotte apela para a imprensa local (Gazeta de Piracicaba, fundada em 1882) e da capital da província, fazendo publicar artigos nos quais, em meio a colocações vigorosas e incisivas, manifesta sua oposição às práticas obscurantistas e retrógradas então vigentes no 
ensino tradicional e prega a educação feminina como via preferencial para a emancipação da mulher. A instalação da ordem das irmãs de São José em Piracicaba é adiada por dez anos: o Colégio de Nossa Senhora da Assunção só seria inaugurado lá em 1893.

\section{5}

Por ocasião de sua viagem a Buenos Aires (talvez a serviço das missões metodistas), em 30 de junho, Marie Rennotte recebe novo passaporte, de número 204, concedido pelo consulado geral da Bélgica no Rio de Janeiro.

\section{8-89}

Colabora com Josefina Álvares de Azevedo (1851- ?) em matérias doutrinárias para o jornal feminista A Familia, publicado na capital paulista desde 1888 (transferido para o Rio de Janeiro em maio de 1889). Rennotte inclui-se, assim, na plêiade de jovens intelectuais reunidas em torno desse periódico, figurando ao lado de mulheres predestinadas a compor, na virada do século XIX para o XX, um quadro da inteligência feminina nacional: mulheres como Anália Franco, Zalina Rolim, Narcisa Amália, Júlia Cortines, Revocata Heloísa de Melo, Maria Clara da Cunha Santos, Prisciliana Duarte de Almeida, Inês Sabino e Júlia Lopes de Almeida.

\section{9}

Aos 37 anos, um ano depois da promulgação da Lei Áurea, a professora deixa o Brasil rumo aos Estados Unidos, onde permanecerá nos próximos três anos (o carimbo

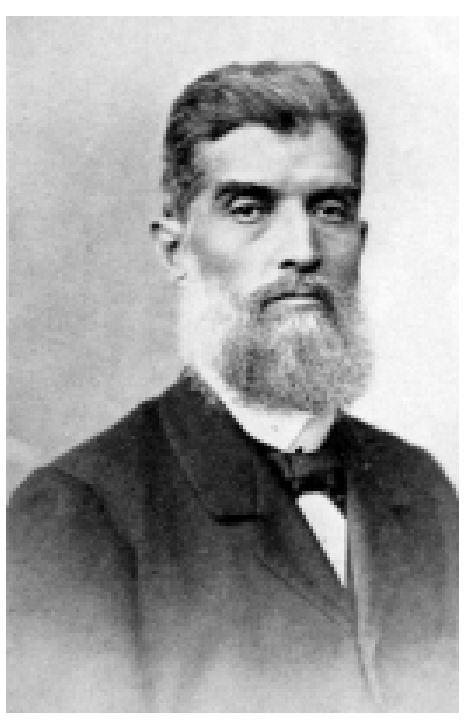

Prudente José de Morais Barros, por volta de 1895 , amigo de Rennotte desde os anos 1880, quando residiam em Piracicaba. aposto ao passaporte pela Secretaria de Polícia da Corte traz a data de 23 de junho). Cinco meses depois, em 15 de novembro, Deodoro da Fonseca proclama a República e, em 14 de dezembro (na ausência da mestra belga, portanto), decreta a naturalização compulsória de todos os estrangeiros residentes no país, "salvo declaração em contrário". Por essa época, acelerase a carreira política de Prudente José de Morais Barros (1841-1902): integrante, até fins de 1889, da junta governativa republicana provisória, torna-se o primeiro presidente do estado de São Paulo (de 1890 a 1891). Nessa curta passagem pela administração estadual, declaradamente inspirado nas experiências pedagógicas do Colégio Piracicabano, ele deflagra radical 
reestruturação do ensino paulista. Tendo como executores iniciais os médicos Caetano de Campos (1844-91) e Cesário Mota (1847-97), a reforma será implementada pelos governos estaduais subseqüentes.

1892

Aos quarenta anos, Marie Rennotte gradua-se em medicina pela Woman's Medical College of Pennsylvania, faculdade criada na cidade de Filadélfia (EUA) em 1850 (o diploma é datado de 5 de maio). Não será certamente a primeira mulher a exercer a profissão médica no Brasil: em 1881, a carioca Maria Augusta Generoso Estrela (1860-1946) já se tornara a primeira brasileira graduada em medicina, em Nova York (EUA); e em 1887, a gaúcha Rita Lobato Velho Lopes (1866-1959) se transformara na primeira médica brasileira formada em seu próprio país (Salvador, BA). A elas seguiram-se outras pioneiras desta ou daquela região do Brasil. Mas, ao que tudo indica, Rennotte seria a primeira mulher médica estabelecida (em caráter permanente) na cidade de São Paulo. Nesse mesmo ano de 1892 nascia, na capital paulista, a futura pedagoga e médica Carlota Pereira de Queiroz (1892-1982). Relataria ter-se inspirado no modelo profissional fornecido pela doutora Marie Rennotte ao dedicar-se a pesquisas clínicas, efetuadas paralelamente a importantes trabalhos de intervenção médico-social. A doutora Carlota Pereira de Queiroz desempenharia, ainda, o papel de primeira mulher deputada federal do Brasil na Constituinte de 1934 e no período transcorrido entre 1935 e 1937.

\section{3-95}

As atividades da recém-formada doutora Rennotte neste intervalo de dois a três anos são esclarecidas por Ana Maria de Revoredo: retorna à França e aperfeiçoa-se em ginecologia, obstetrícia e neonatologia; freqüenta os hospitais parisienses Hôtel-Dieu, reestruturado em meados do século XIX pelo célebre Armand Trousseau (1801-67), e Saint-Louis, de reconhecida eficiência no tratamento de doenças venéreas e cutâneas. No Brasil, Prudente de Morais é eleito presidente da República para o quadriênio 1894-98, depois de ter presidido a Constituinte de 1891 e de atuar como senador na legislatura de 1891-94; empossado em 15 de novembro de 1894, torna-se nosso primeiro presidente civil, encerrando o lustro de militarismo vigente sob Deodoro da Fonseca e Floriano Peixoto.

1895

Decidida a fixar-se definitivamente no Brasil, Rennotte retorna à capital federal onde, em 26 de março, obtém a validação de seu diploma. Perante banca organizada pela cadeira de higiene e mesologia da Faculdade de Medicina e de Farmácia do Rio de Janeiro, chefiada por Benjamin Antônio da Rocha Faria, Rennotte defende tese intitulada Influência da educação da mulher sobre a medicina social, publicada pela editora carioca Typographia Aldina. Já na capital paulista, em 
meados daquele mesmo ano, é admitida na recém-instituída Sociedade de Medicina e Cirurgia de São Paulo, entidade que elegera em 24 de fevereiro seu primeiro presidente, o culto cirurgião fluminense Luís Pereira Barreto (1840-1923).

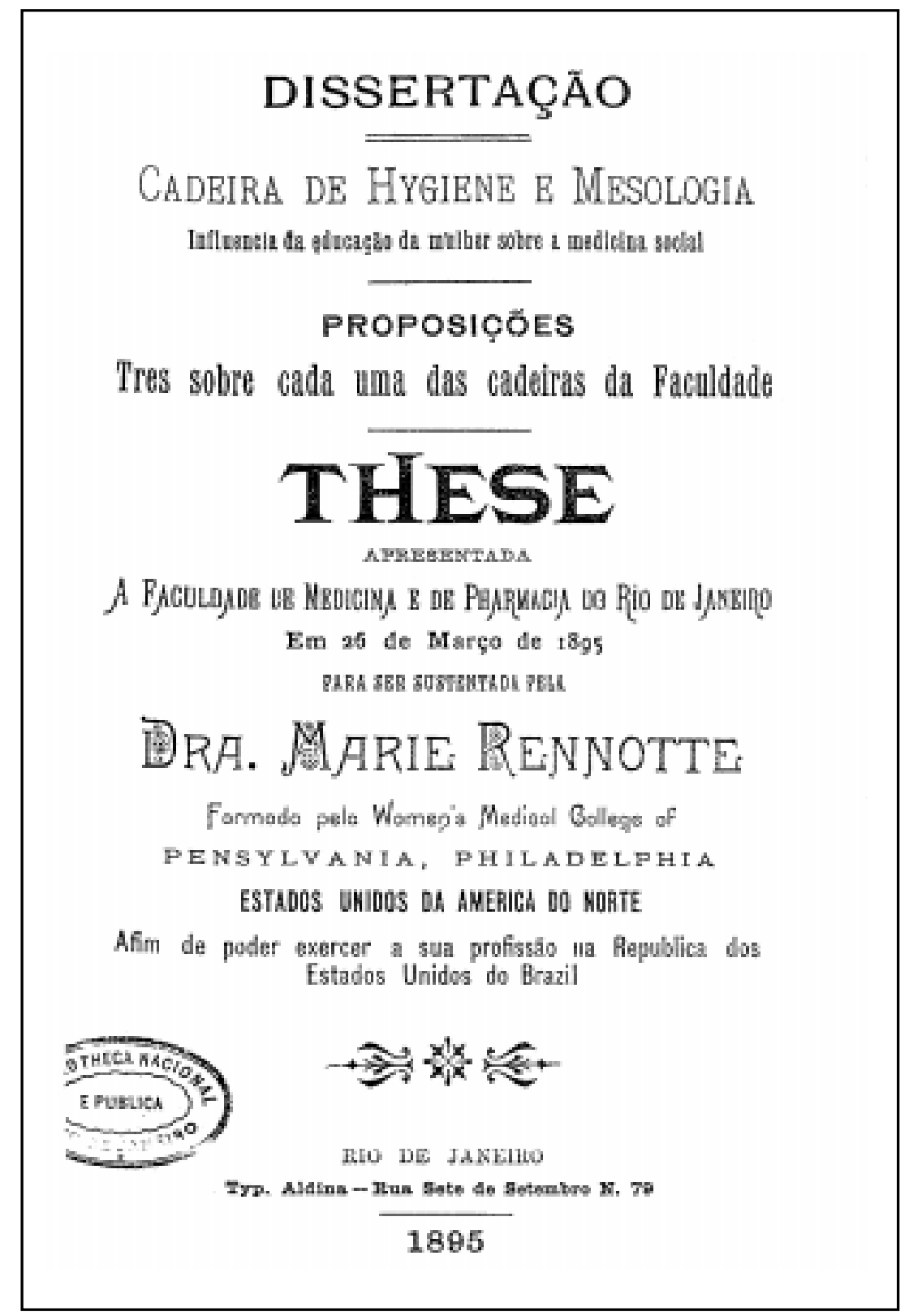

Folha de rosto da tese de Maria Rennotte, apresentada à Faculdade de Medicina e de Farmácia do Rio de Janeiro, em 1895. 


\section{5-97}

São Paulo é a cidade que Marie Rennotte escolhe para atuar. Na substituição acelerada da mão-de-obra escrava pelo braço do imigrante estrangeiro, a metrópole do café salta de cinqüenta mil habitantes, em 1886, para os 240 mil recenseados em 1900. Agudizam-se os problemas preexistentes no saneamento básico e na saúde da população que se aglomera desordenadamente nos bairros centrais. A médica intervém nesse universo caótico em todos os níveis, atendendo mulheres mais abonadas a domicílio ou em consultório particular, e as desfavorecidas em ambulatórios ou enfermarias hospitalares. Testemunha ocular dessa atuação, Jorge Americano relata, em suas memórias, que figuras notórias como a parteira madame Laborde e a doutora Rennotte chegavam às residências de seus clientes em tílburis, carregando volumoso instrumental obstétrico; contribuíram, assim, para alimentar a crença infantil de que as crianças recém-nascidas não se originavam de suas mães: eram trazidas para suas casas dentro daquelas bojudas maletas.
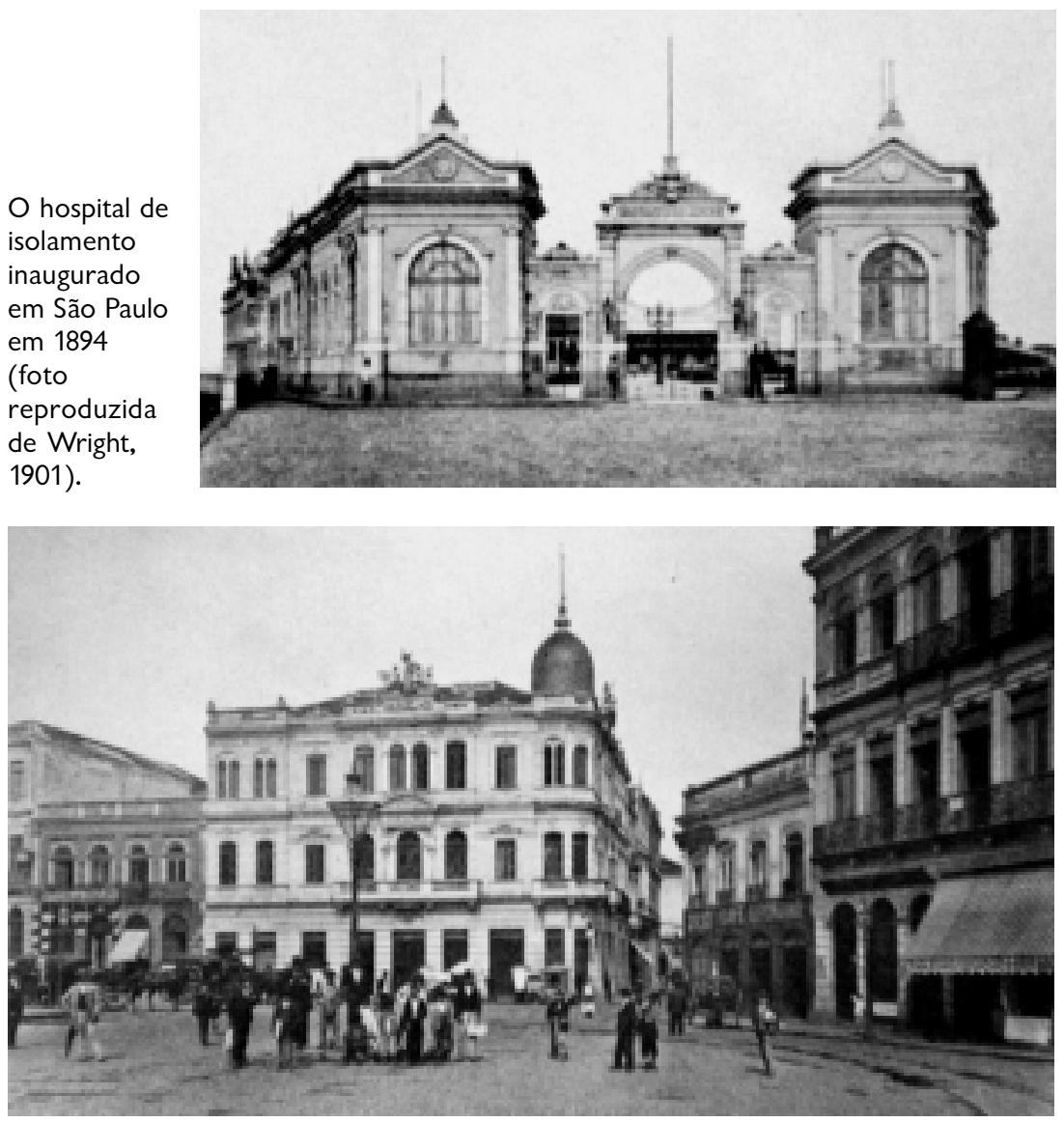

Tomada do Largo da Sé por volta de 1900. O prédio com cúpula situado na esquina da rua Direita abriga a Casa Baruel, mantenedora de uma das mais célebres drogarias de São Paulo na belle époque (foto reproduzida de Wright, 1901). 


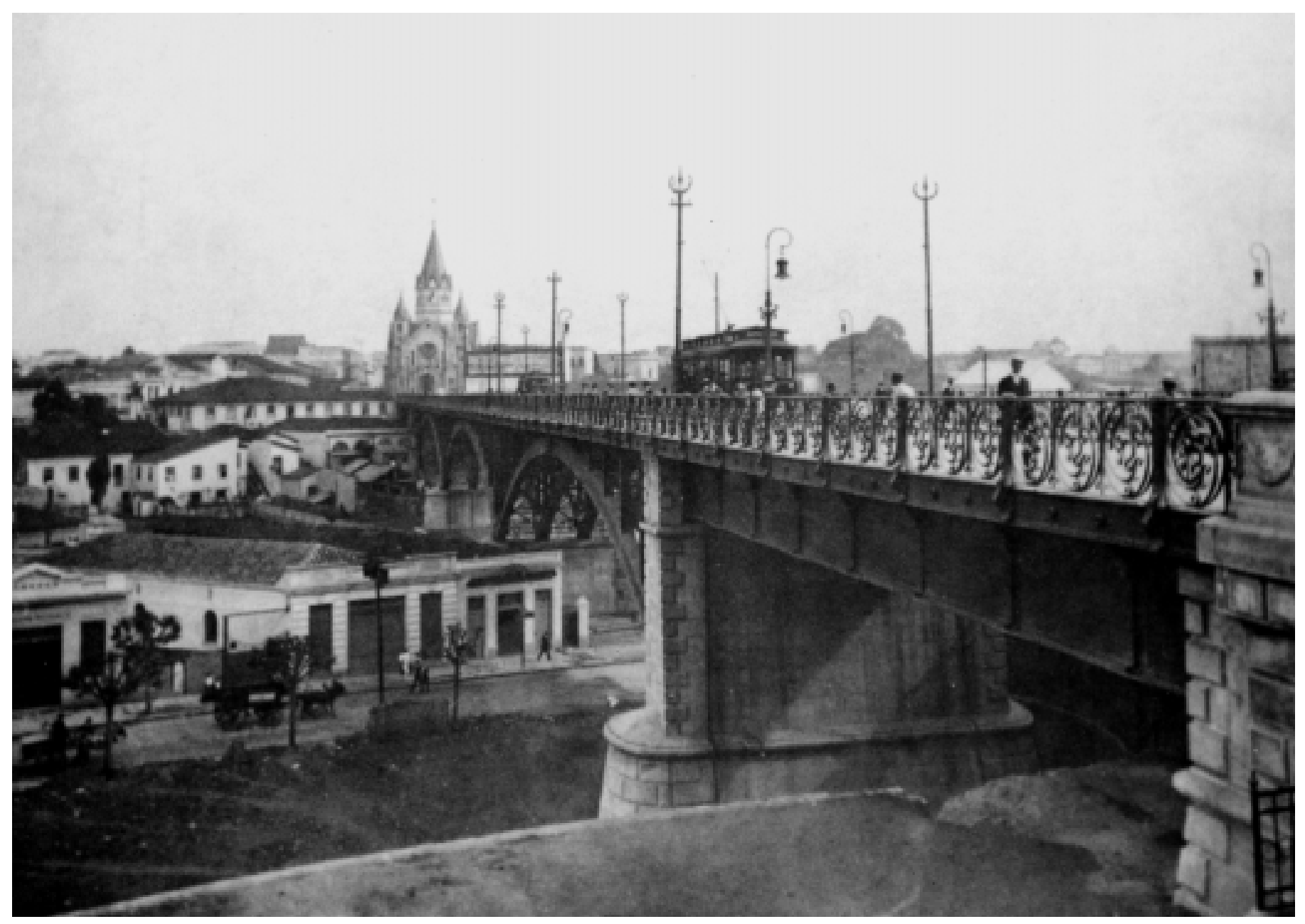

Viaduto Santa Ifigênia, com a igreja do mesmo nome ao fundo, em meados de 1910. A Escola Livre de Farmácia, inaugurada em 1899, fica na ladeira de Santa Ifigênia (foto reproduzida no álbum Sociedade Hípica Paulista: 75 anos, organizado por Margarida Cintra Gordinho, 1987).

1896

A imprensa paulistana veicula, em outubro, a informação de que a doutora Marie Rennotte apóia abertamente a professora Leolinda Daltro (c. 1860-1935) em sua proposta, muito polêmica na capital federal, de embrenhar-se pelos sertões de Goiás para dar assistência às populações indígenas ameaçadas de extinção.

1897-1900

Neste período, é editada em São Paulo a "revista literária dedicada à mulher brasileira", $A$ Mensageira, dirigida pela poetisa mineira Prisciliana Duarte de Almeida (1867-1944). No primeiro número, Marie Rennotte é elogiada por seu trabalho junto à recém-criada Maternidade de São Paulo, dirigida, desde sua fundação, em 1894, pelo doutor Bráulio Gomes (18541904). O no 9 veicula breve ensaio da médica, no qual retoma sua exortação pela maior participação feminina na vida social, tema já abordado na tese de doutoramento de 1895. 


\section{A MENSAGEIRA}

\section{Revista literaria dedicada á mulher brazileira Direstera - Presciliana Duarte de Almeida}

Esta revista garante a sua publicagito durante um anno. Publica-se nos dias 15 e 30 de cada mex.

\begin{tabular}{c|c|c}
\hline $\begin{array}{c}\text { Pagamento } \\
\text { adlantado }\end{array}$ & $\begin{array}{c}\text { Preço da assignatura, 12\$000 por anno } \\
\text { Endorego }: \text { Rea des Estudantes N. 23 }\end{array}$ & $\begin{array}{c}\text { Numero avulso } \\
\text { Rs. } 15000\end{array}$ \\
\hline
\end{tabular}

A MEVTSAGETRA

Quer seves omis, aakat entrelbs brithasdo ece tuplo felper

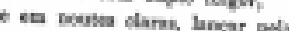

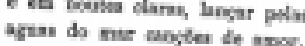

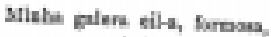
pare a lafrito visjer... OO cos ismoz-se ear do iten o tera, ites a mer).

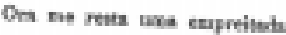
ges wo ves, mefrenda, execlair: - daw stes a taiaka arado, dierer adeu - apdo partir.

Diser sdeas - wea ter cangen.

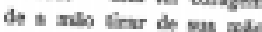
- periaglar bapa a ringon.

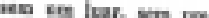

Extanis irei. Ges, las ovends. an wivece nise te alongal po sea palado - nirma expdr wo pat de eiperen buriteal.

All dentro the powos o lea dere 9 sapapn tois iflevisas:

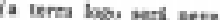
ides o ou, ilen a ate! Casbeso ne Casvatuo k

If muther 6 uma forca activa na sociedade

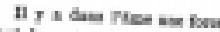

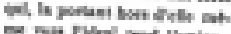
sesunese te be pals.

Hoje, que a instruesso priocipis a expallizr-se reais gernilssante; goe se froem estidos mals profundrs yue " expiribs este agcase lirm du oceupa-ab tauto da sciencia, mo. rimento e das forças que o preduzen, o homem ainds, devido razces que nilo se explitan, desonida de una foça qqee elle tem sob a sua mis - eats forta sulber.

Se na linguages da mecanica dix finimos a forças a causs que de. tarmina o morimento on as sues modifieagles podentos on as suscs modifbeaples podestos dizer que a mulher of a ngeate que impelle a nma gerapilio os saorimentos ou ton. descis para 0 bem on para o mal. Debeixo da acoiso oontisas de 8 sa nilia a criança sagne saburalmente - diroscilo que esta the traga ou impot, o aecessariamenta o fila more-se as direosto da força uaiea. I qual alle eath submettida.

Quasdo ea dipo: o corpo submettido 1 uma borça anica more. se na direcolo desta for move preterdo negir a açalo do poi nem exchint 0 on dispensal-o do derer de evidar da edscacilo de ans $\mathrm{f}$ Ibss, nllo; mas sian, stencionar esta facto enasi peral gque ao pai incumbinds a tarafa de subniastrar is necresidedes da farnilin, nito the t possirel, muitas veses, por cudse de anseacia tocyads ou sutras ra. ales, ter oonstantemente sena filaos debaixo de seus ollas; portanto a sobre a milh que meabe abte deres.

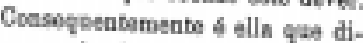
rige, que implanta, inprime as pr. cteiras impreswoses, os primeiros sentíteotos so earapio don filhos.
142

A Mevsagema

Queremoa que esta acçĩo que ells optra sobre as jowens eresturas seja protaitosa, util a humanidade? Dewemes trabelhar para que o espirito da malber seja esclarecids; para gav sua iabelligeneia seja os. tirsia, afim de que 6 lla saibs dis. tinguir o bem do mal, o falso ds justo, a verdude da mentira 6 da saperstiçaso; afin de que ulla seje eapax de formar o carracter de seus filbos colveado, eccuminhando os sous pensameotos pare o bella, 0 tom e o real; 6 seceseario emfir dar a realber o pio do wha gue e a instracolto basivoda sobre forodawerto de irma moral ell. Cora esta arma que vence som espallar sanges, que conqualats sen devas. tar eu sooslar, a mulber torna-at forte, +6 entlin que se pode dizer eos Legouvé:

co temines! e'vet a bort qu'os vous mormme troibles

$A^{\prime}$ la roix de vons carur wous thes intripides.

- Be a istensidade de vera for pa se aptecis comparado ou re. feriodo-a a usia cutra forch de igual saturees bomida poe ualidade psde-se factlmente avaliar a supe riscidade ds mulher edacada (no rendacteiro sentido) sobre a igno raseb, eonevilerando o que pode, em mea cass, a prudencia da melaer, para sustental-a, para nell fower nasoer on manter o ocafoe- tawel, o bes reinar a $p$ Justo of tris ou me me esprim aqpella qu morimento tribuindo * accelerragio simento, a Egrarante a bido cusitran ou extiugas progreses,

Instruind, wha nella 1 panbeine, $n$ nko uxicane filhos, mas wise, capax chefe, de det funilia $e$ os celturn do $e$ sultarí que, as do marid desta constin piritos, surgi caltalabe de $c$ posentes goe enforçoa, mas rimesto a res 
a

, o ben eetar, para no lar fazer r a pas, a darmonia, a unilo. to of pois, chnesar force sto10 modorn ise eu assim posso sprimir) a mulher instraids, la que actua as sentido do nento on adisotamento, conado total ea pareialmerte a a rmgio ou produeckio deste mor to, e força de resistencin on nte aysells จae actax do senantrario; isto a dimiauindo ningseindo o morimanto on ses,

ruindo a nulber, o domest iella niko soatente uma come $\mathrm{n}$, mais aiteda, us auxilio: Geanente uma ama para seus mas sim, atra rerdadeira upax, no easo da morte do 16 defeater es interesses do e as bens dos orpbatos. $\mathrm{Da}$ do espinito do mulher reque, entre as suas idías e maride haverd afteidade a xubinaçlo su uaitio doe tosurgiri a forca ; a força re. de dows agentes ou conI qqee não neutralisario sets mas sias acceletrorâo o mo.

n rearche de progreses.

4. Frsesurtr

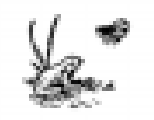

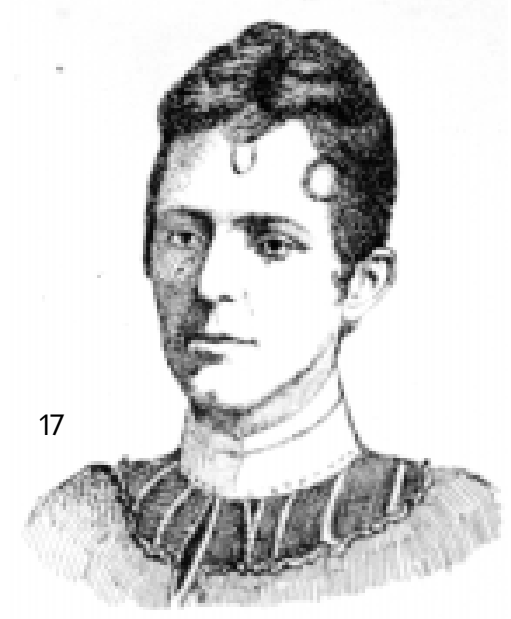
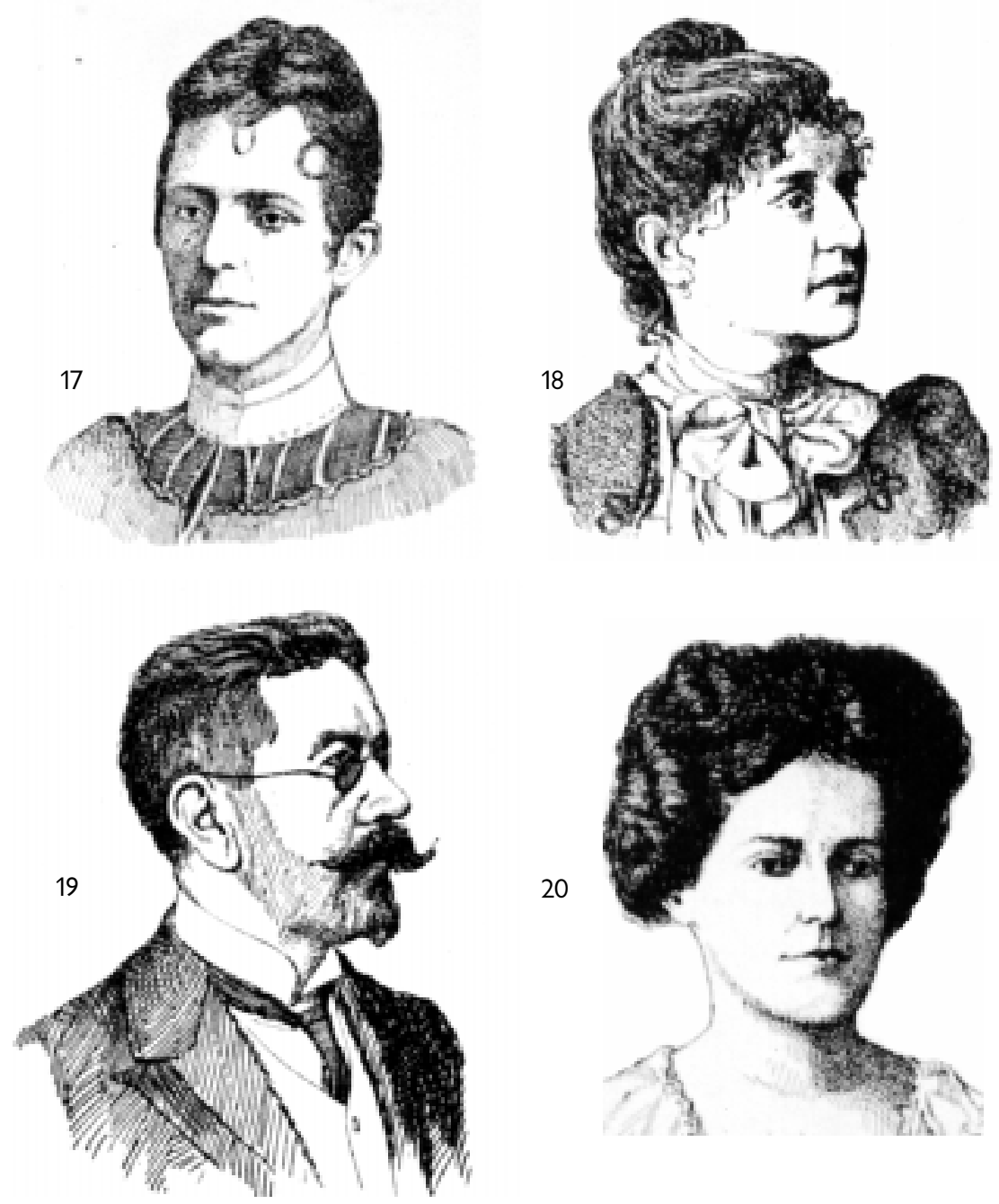

Entre os colaboradores de A Mensageira, Rennotte e Anália Franco destacam-se, entre outras figuras, como a diretora da revista, Prisciliana Duarte de Almeida ( $n$ 18); seu marido, Silvio de Almeida ( $n^{\circ}$ 19); a educadora Zalina Rolim ( $n$ - 17) e a poetisa Francisca Júlia da Silvia (n²0), nos desenhos acima (ilustrações reproduzidas de Freire, 1916). 


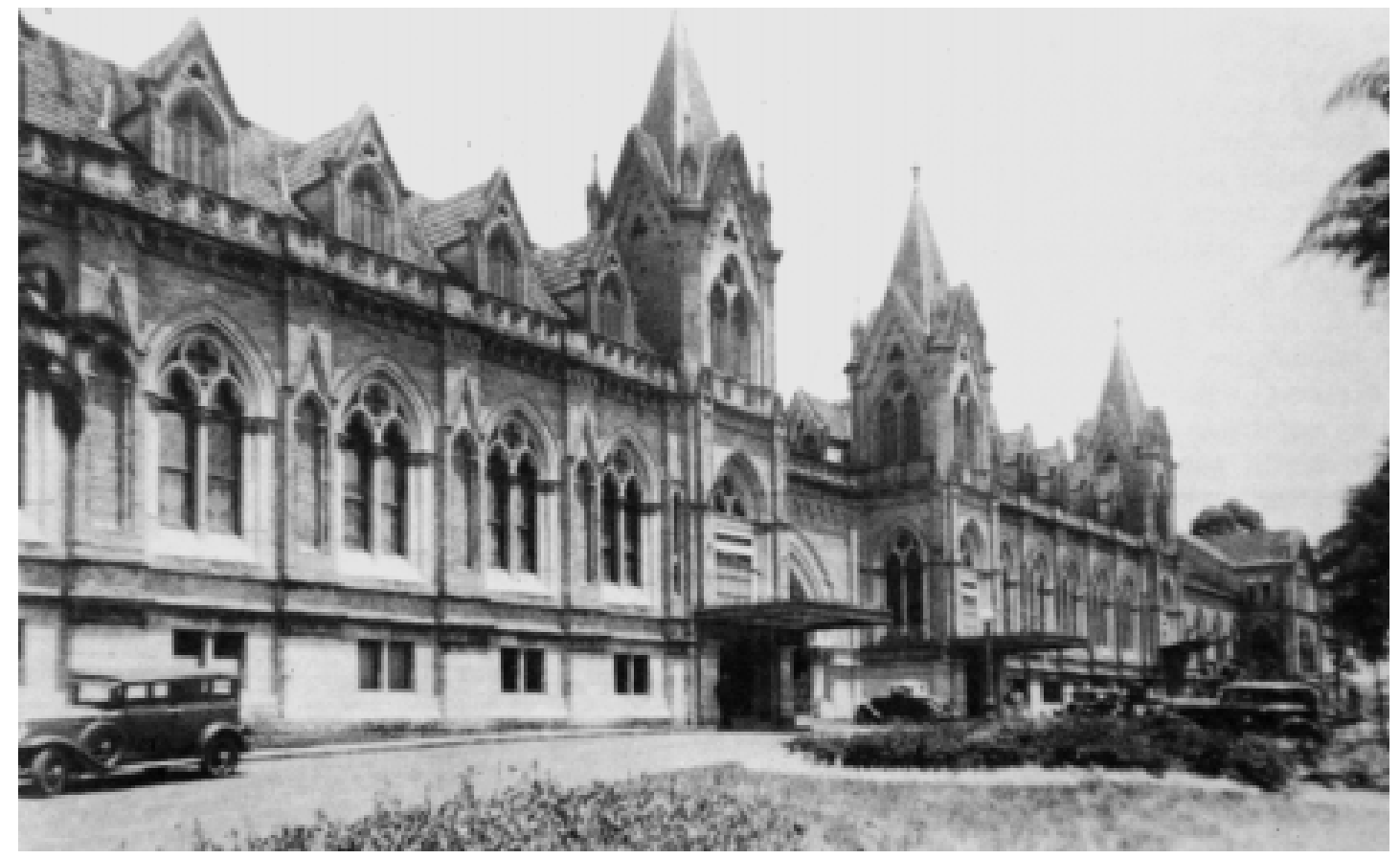

Fachada da Santa Casa da Misericórdia de São Paulo na década de 1920 (foto reproduzida de Lacaz, 1985).

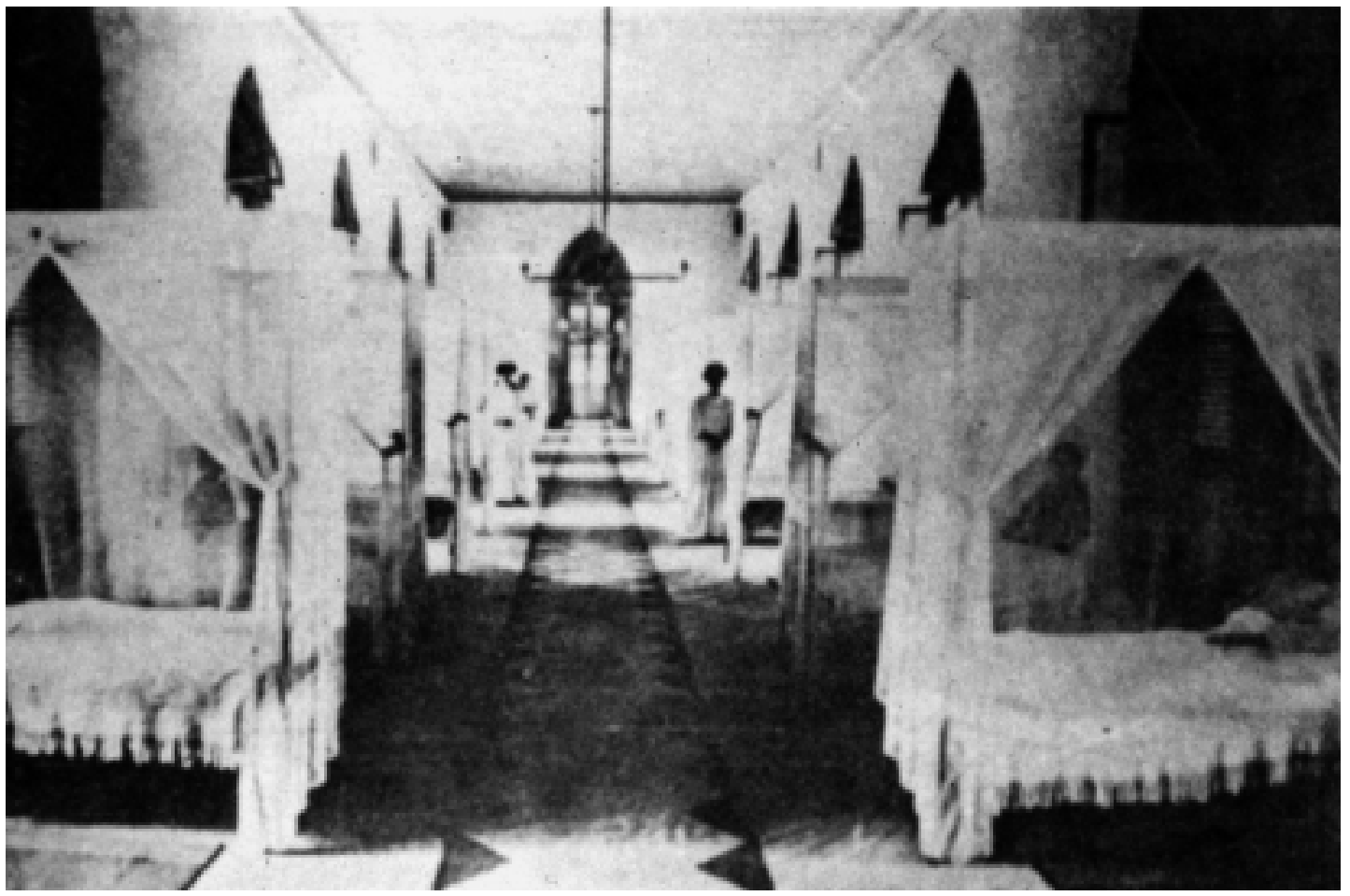

Enfermaria ginecológica de mulheres na Santa Casa de São Paulo, onde Renotte atuou como médica (foto repoduzida de Carneiro, 1986). 


\section{8}

A paulista Pérola Byington é mencionada no no 7 de A Mensageira como pioneira, ao lado de Irene Ferreira Lopes, na freqüência feminina ao curso anexo à Faculdade de Direito de São Paulo, preparatório para o ingresso em instituições de ensino superior. Nascida Pérola Ellis McIntyre (1879-1963), era filha de uma ex-aluna do Colégio Piracicabano, a educadora Mary Ellis McIntyre (c. 1860-1928), emigrada do Sul dos Estados Unidos para o Brasil ainda criança. Diplomada pela Escola Normal Caetano de Campos, Pérola Byington chegou a exercer o magistério, mas deixou de lado a intenção de se tornar advogada para se casar, em 1901, com o rico industrial norte-americano Alberto Jackson Byington. Foi a mais notória ativista 'leiga' no setor de promoção de saúde na São Paulo da primeira metade do século XX, especialmente no âmbito da atenção à saúde materno-infantil, tornando-se por esse motivo membro honorário da Sociedade Brasileira de Pediatria e inaugurando, poucos anos antes de seu falecimento, o hospital paulistano denominado, em sua homenagem, Hospital Pérola Byington.

\section{9}

Instalação, em 13 de fevereiro, da Escola Livre de Farmácia de São Paulo, dirigida pelo médico Bráulio Gomes, que se propunha, inclusive, a proporcionar ali maiores oportunidades de profissionalização às mulheres. O evento contou com ampla cobertura de A Mensageira, no $\mathrm{n}^{\mathrm{o}} 26$.

\section{1}

Marie Rennotte torna-se, em 4 de maio, a primeira mulher admitida no Instituto Histórico e Geográfico de São Paulo (IHGSP), fundado em 1894 por intelectuais radicados na capital paulista. Apresentada aos consócios por Dinamérico Rangel e por dois escritores estreitamente vinculados a dona Viridiana Prado, Orville Derby e um dos filhos mais novos da matriarca, Eduardo Prado (1860-1901), ali iria conviver com influentes colegas médicos, como o já mencionado Pereira Barreto, ou com mestres de renome, como o professor Sílvio de Almeida (18671924), marido de Prisciliana Duarte.

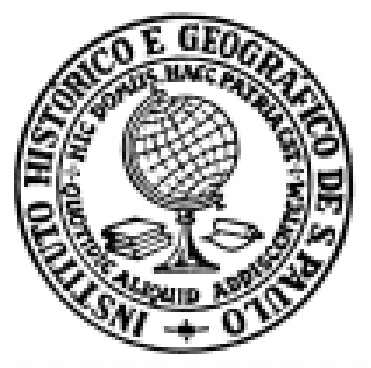

Maria Renotte foi a primeira mulher admitida, em 1901, no Instituto Histórico e Geográfico de São Paulo. O brasão foi criado pelo professor João Vieira de Almeida quando o instituto foi fundado, em 1894. 
1902

Morre em Piracicaba, em 3 de dezembro, o ex-presidente Prudente de Morais. Em abril do ano seguinte, o jornal O Estado de S. Paulo homenageia-o abrindo subscrição para a execução de um monumento tumular: parte da doutora Marie Rennotte a contribuição mais vultosa, no valor de quinhentos mil-réis (meio conto de réis).

1905

Em 1ํ de março torna-se sócia efetiva da Associação Médica Beneficente de São Paulo, então presidida por Arnaldo Vieira de Carvalho, que tinha como secretário e tesoureiro, respectivamente, os colegas médicos Teodoro Bayma e Nicolau de Morais Barros (sobrinho de Prudente de Morais). Em 9 de junho 1905, recebe o diploma de sócia benemérita do Asilo e Creche da Associação Feminina Beneficente e Instrutiva (de São Paulo), entidade assistencial fundada e dirigida por uma amiga, a pedagoga espírita Anália Franco (1853-1919). Radicado em São Paulo desde os primeiros dias da República, analise e organiza, ao longo de três décadas de trabalho incessante, uma das mais notáveis redes de amparo a crianças e jovens carentes de que se tem notícia no país.

1908

No dia 5 de dezembro é oficializada a fundação da Cruz Vermelha Brasileira, cujo quadro inaugural conta com Oswaldo Cruz (1872-1917) como seu presidente de honra e com Marie Rennotte como organizadora da regional paulista.

1912

Torna-se, em 20 de dezembro, sócia honorária da União Cooperativa Familistariana do Brasil (sediada no Rio de Janeiro), instituição "humanitária, filantrópica e patriótica, cujo fim é a união de todos aqueles que sentem a necessidade de um melhor estado de civilização". O curioso diploma conservado pelo IHGSP, contendo alusões ao célebre familistério de Jean-Baptiste-André Godin (1817-88) e à democracia cristã de Leão XIII (1810-1903), sugere uma possível filiação da médica à corrente neocristã derivada do socialismo utópico de Charles Fourier (1772-1837).

\section{3}

Instalação da Faculdade de Medicina de São Paulo, sob a direção do antigo colega de Marie Rennotte, Arnaldo Vieira de Carvalho. A aula inaugural, em 2 de abril, é proferida por Edmundo Xavier, lente da Escola Livre de Farmácia de São Paulo e futuro diretor da nova faculdade. Em 1918, formará sua primeira turma, na qual já se incluem duas médicas, Délia Ferraz e Odete Nora. Ao se casarem com dois colegas de turma, respectivamente Flamínio Fávero e Altino Augusto de Azevedo Antunes, assumem os nomes de Délia Ferraz Fávero e Odete Nora de Azevedo Antunes. 


\section{8-19}

No verão de 1918-19, a gripe espanhola atinge o Brasil. Em São Paulo, como no Rio de Janeiro, contam-se aos milhares as vítimas fatais da epidemia, entre elas um colega da Santa Casa (o doutor Teodoro Bayma) e uma querida amiga da doutora Rennotte (a professora Anália Franco). Ainda assim, a médica permanece na capital paulista dando assistência a suas pacientes.

\section{2}

Ao completar setenta anos, Marie Rennotte profere, em 6 de fevereiro, no IHGSP, uma conferência "calorosamente aplaudida" em homenagem a Isabel de Bragança (1846-1921), herdeira do trono brasileiro, falecida três meses antes. Ao final da apresentação, a médica é elogiada por um consócio católico, monsenhor Ezequias Galvão da Fontoura (18421929), fato que ilustra a prática (entre ambos, pelo menos) de uma postura ecumênica avançada para a época. Na semana seguinte, em 13 de fevereiro, a doutora Rennotte oficializa a doação ao instituto de um aparelho projetor de transparências.

\section{3}

Em sessão datada de 5 de março, Rennotte disserta, perante os consócios do IHGSP, sobre a 'Mãe dos brasileiros', Ana Néri, em conferência "copiosamente ilustrada com projeções luminosas". A diretoria da entidade acata um pedido da oradora: que se constituísse uma comissão para estudar a viabilidade da construção de um monumento em homenagem à pioneira da enfermagem no Brasil. Integram essa comissão, designada na mesma data, Marie Rennotte, Pedro Dias de Campos e Félix Soares de Melo.

\section{4}

Um levante militar tenentista, deflagrado em 5 de julho, mantém a população da capital paulista à mercê de combates que persistem até o final do mesmo mês. Ocupada pelos revoltosos, São Paulo sofre o bombardeio das tropas legalistas federais que haviam sitiado a cidade, chegando a quinhentos o número de mortos e a cerca de cinco mil o número de feridos (civis, em sua maioria). O Hospital da Santa Casa da Misericórdia é esvaziado para o atendimento exclusivo das vítimas do conflito, chegando a abrigar três mil pessoas; mas a setuagenária doutora Rennotte não se encontra entre os médicos que lá permaneceram para dar atendimento aos feridos: ela encarregara-se de organizar pessoalmente uma enfermaria extranumerária improvisada nas dependências do antigo Teatro Colombo, localizado no bairro do Brás.

1925

Comparecendo à cerimônia realizada em 26 de março na sede nacional da Cruz Vermelha Brasileira (Rio de Janeiro), durante a qual 
se inaugura um retrato de Ana Néri, Marie Rennotte encerra a solenidade discursando a respeito da vida e da obra da homenageada.

1929

Em sessão datada de 25 de outubro, Rennotte profere nova conferência no IHGSP, versando sobre o tema 'A mulher brasileira na história', em que menciona a lendária figura de Joana d'Arc, contrapondo a ela a heróica atuação das brasileiras Anita Garibaldi e Ana Néri.

1932

Já com oitenta anos completados em fevereiro, a doutora Rennotte não tem mais condições de atuar diretamente no atendimento aos paulistanos atingidos pelos conflitos que se seguiram à eclosão da revolução constitucionalista e que persistirão ao longo dos meses de julho, agosto e setembro de 1932. Quem assume papel semelhante àquele desempenhado pela médica belga na revolução de 1924 é a doutora Carlota Pereira de Queiroz, que se coloca à frente da seção paulista da Cruz Vermelha para organizar um grupo de setecentas voluntárias que receberão rápido treinamento especializado para o atendimento do grande número de feridos abrigados na capital do estado.

1935

Idosa, "surda e quase cega", Marie Rennotte visita os consócios do IHGSP em 8 de outubro para pedir que se tomem providências no sentido de preservar uma velha carruagem que servira, em passado remoto, como meio de transporte ao regente Feijó e ao imperador Pedro II.

1938

Em decorrência da repercussão obtida na imprensa paulistana por uma campanha encetada pelo jornalista Mário Guastini (1884-1949), o interventor federal paulista José Joaquim Cardoso de Melo Neto assina decreto concedendo à médica octogenária, desprovida de recursos e "em precárias condições", uma pensão vitalícia no valor de mil cruzeiros mensais, quantia suficiente para uma manutenção condigna.

1942

Marie Rennotte morre na madrugada ou na manhã do sábado dia 21 de novembro, e não na data até agora divulgada de 23 de novembro pelos registros do IHGSP. O corpo é velado na casa situada na rua João Moura, 427 (em Pinheiros, SP), nas proximidades do local onde estava sendo construído o moderno Hospital das Clínicas da Faculdade de Medicina da Universidade de São Paulo (USP), inaugurado em 1944. O sepultamento ocorre na tarde do mesmo dia, no Cemitério dos Protestantes (da rua Sergipe, Consolação). Estamos em plena Segunda Guerra Mundial. O Estado de S. Paulo publica o primeiro necrológio no 
dia seguinte, em meio a um noticiário que destaca os avanços das forças aliadas no front do Pacífico Sul, e que evidencia, no Brasil do Estado Novo, os fortes vínculos existentes entre Vargas e o Departamento de Imprensa e Propaganda (DIP). Em 24 de novembro, o mesmo diário paulistano publica matéria assinada por Mário Guastini com reminiscências pessoais. Em 30 de dezembro, uma reportagem do mesmo jornal é complementada pela transcrição do discurso com o qual Ana Maria de Revoredo homenageara a doutora Rennotte, em nome da Cruz Vermelha Brasileira, durante cerimônia realizada na capital paulista no início de dezembro.

\section{3}

Em 5 de fevereiro, é a vez do IHGSP reverenciar a memória dos consócios falecidos no ano anterior, encarregando-se Félix Soares de Melo de fazer o elogio fúnebre de Marie Rennotte.

\section{1}

Por iniciativa de Nelly Martins Ferreira Candeias, que, em janeiro de 2002, assume a presidência da instituição, tornando-se a primeira mulher a exercer o cargo, o IHGSP comemora o centenário da admissão da doutora Rennotte, em sessão solene realizada no dia 4 de maio. Especialmente convidadas para o evento, estiveram presentes, entre outras personalidades, a veterana historiadora Myriam Ellis (consócia admitida em 1951), a ex-senadora paulista Eva Blay e a professora Zuleica Mesquita (pesquisadora da história do Colégio Piracicabano). Proferiram conferências pertinentes à efeméride, após dissertação introdutória da professora Nelly Candeias, Maria Lúcia Spedo Hilsdorf (sobre 'Rennotte educadora') e Maria Lúcia de Barros Mott (sobre 'Rennotte médica'). Na mesma ocasião, inaugura-se exposição iconográfica idealizada por Nelly Candeias e Ricardo Bogus, e executada por Eliane Cristina Lopes Nassif, Leda Rodrigues Ramos Lamotta e Brás Ciro Gallotta. São exibidos os documentos originais conservados pelo instituto (todos descritos na presente cronologia) e ressaltadas as presenças, na São Paulo novecentista, daquelas três ilustres seguidoras da mestra belga: Mary Ellis McIntyre, sua filha Pérola Byington e a médica Carlota Pereira de Queiroz.

2002

Comemoração, em 11 de fevereiro, do sesquicentenário do nascimento de Marie Rennotte. 


\section{BIBLIOGRAFIA ANALÍTICA}

Alves, Odair Rodrigues

Amaral, Antônio

Barreto do

Americano, Jorge

Assis, José Eugênio de Paula

Bernardes, Maria Thereza Caiuby Crescenti

Bittencourt, Adalzira

Candeias, Nelly

Carneiro, Glauco
Os homens que governaram São Paulo. São Paulo, Livraria Nobel/Edusp, 1986. Compêndio útil para a caracterização dos governos paulistas no período transcorrido entre 1889 e 1942, isto é, de Prudente de Morais até a gestão do interventor Fernando de Sousa Costa, durante a qual ocorre o falecimento de Rennotte (pp. 113-56).

Dicionário de história de São Paulo. São Paulo, Governo do Estado de São Paulo, 1980. Condensando em um só volume várias décadas de pesquisas realizadas pelo historiador Barreto do Amaral (1903-95), este dicionário facilita o trabalho de investigação ao trazer verbetes tanto de natureza biográfica (Prudente de Morais, Rangel Pestana, Caetano de Campos, Cesário Mota, Bráulio Gomes, Arnaldo Vieira de Carvalho, Orville Derby, Eduardo Prado etc.) como de natureza temática (Escola de Farmácia, Faculdade de Medicina, governo provisório, Instituto Histórico e Geográfico, Santa Casa da Misericórdia de São Paulo etc.).

São Paulo naquele tempo (1895-1915). São Paulo, Saraiva Livreiros Editores, 1957. Primo de Prisciliana Duarte, Jorge Americano (1891-1969) publicou, entre 1957 e 1963, uma trilogia memorialística da qual este é o primeiro volume. Paulistano de nascimento, um dos primeiros reitores da USP (criada em 1934), Americano relembra a atuação de parteiras (como madame Laborde) e obstetras (como a doutora Rennotte) que faziam o atendimento domiciliar local na virada do século XIX para o XX, contribuindo para enriquecer o imaginário infantil com fantasiosas teorias a respeito do nascimento dos bebês (p. 483).

Prudente de Morais: sua vida e sua obra. São Paulo, edição do autor (s. n. t.), 1976. Detalha, nas pp. 257-8, o episódio relativo à subscrição aberta pelo jornal O Estado de S. Paulo para a construção do monumento-túmulo de Prudente de Morais, em 1903.

Mulheres de ontem?: Rio de Janeiro - século XIX. São Paulo, T. A. Queiroz Editor, 1989. Resultante da tese de doutoramento (USP, 1984) orientada por Maria Isaura Pereira de Queiroz, este livro mapeia a produção literária feminina brasileira da segunda metade do século XIX, aí incluindo excertos das diferentes colaboradoras do jornal de Josefina Álvares de Azevedo, A Família (destacando-se menções a Marie Rennotte nas pp. 114 e 208; e, na p. 135, nota biográfica acompanhando a transcrição de um excerto datado de 1889).

A mulher paulista na história. Rio de Janeiro, Livros de Portugal, 1954. Inclui informações pouco precisas, mas muito interessantes, à medida que a autora baseia-se freqüentemente em fontes orais ou tradicionais da própria comunidade paulistana, a respeito de Anália Franco (pp. 145-9), Pérola Byington (p. 155), Viridiana Prado (pp. 178-80) e Carlota Pereira de Queiroz (p. 281).

'Em nome da mulher'. Jornal da USP, São Paulo, ano XV, no 550, 14 a 20 de maio de 2001, pp. 10-1. Texto correspondente à conferência proferida pela autora na cerimônia realizada no IHGSP, por iniciativa dela mesma, por ocasião do centenário da admissão de Marie Rennotte na entidade.

O poder da misericórdia: a Irmandade da Santa Casa na história social e política da cidade de São Paulo - 1560-1985. São Paulo, Press Grafic, 2 vols., 1986. História da Santa Casa da Misericórdia paulistana, com especial enfoque no relacionamento entre seus dirigentes e a maçonaria; importante fonte de informação a respeito das atividades do segundo dirigente médico da Santa Casa, Arnaldo Vieira de Carvalho, formado no Rio de Janeiro em 1888, diretor clínico daquele hospital desde 1894. Nas pp. 440-1 do vol. I mencionam-se nominalmente os 12 médicos adjuntos que compõem o corpo médico de 1906, entre eles Nicolau de Morais Barros e Teodoro Bayma, além da própria Marie Rennotte. No mesmo vol. I, pp. 455-8, descrevem-se as dificuldades sofridas 
MARIE RENNOTTE, PEDAGOGA E MÉDICA...

Cintra Gordinho, Margarida (org.)

Corrêa, Mariza

Cunha, Maria Iza Gerth da

De Luca, João

Bosco Assis

De Luca, Leonora

Freire, Laudelino

Goldman, Frank P.

Gussi, Alcides Fernando pela instituição durante a gripe espanhola (aí incluída a perda de Teodoro Bayma); já no vol. II, pp. 468-80, delineia-se o quadro provocado pelas revoluções de 1924 e 1932 na capital paulista.

Sociedade Hípica Paulista: 75 anos.

São Paulo, Marca d'Água, 1987.

'Os índios do Brasil elegante \& a professora Leolinda Daltro'. Revista Brasileira de História, São Paulo, vol. 9, no 18, ago.-set. 1989, pp. 43-65. O vínculo entre a controvertida pedagoga baiana Leolinda Daltro e a médica belga recémestabelecida na capital paulista é confirmado neste artigo, em que se comenta fato divulgado pela imprensa paulistana em outubro de 1896: a doutora Marie Rennotte ("uma amiga da instrução, isto é, do povo"), abre uma lista de subscrição pública oferecendo à pedagoga um auxílio imediato no valor de cem mil-réis (comprometendo-se a continuar contribuindo mensalmente com a quantia de quarenta mil-réis, se preciso fosse) para o financiamento da expedição que Leolinda efetivamente levará a cabo, com o objetivo de dar instrução não-sectária a indígenas semi-aculturados dos sertões de Goiás.

Educação feminina numa instituição total confessional católica: Colégio Nossa Senhora do Patrocínio. Dissertação de mestrado, São Paulo, FFLCH-USP (mimeo.), 1999. São de particular interesse na tese dessa historiadora da educação as considerações contidas no primeiro capítulo ('A congregação de São José de Chambéry e o ideal de difusão educativa', pp. 16-46), relativas aos pressupostos ideológicos e político-religiosos que norteavam o ensino ministrado por esse conhecido colégio feminino da cidade de Itu, situado em campo antagônico com relação às propostas laicas e progressistas do Colégio Piracicabano.

'Homenagem à dra. Marie Rennotte (1852-1942)'. Suplemento Cultural no 119 do Jornal da Associação Paulista de Medicina, set., pp. 4-5, 2001.

Reportagem relativa à cerimônia realizada pelo IHGSP em 4.5.2001, acompanhada de análise do significado da atuação de Marie Rennotte como educadora e médica (incluindo reprodução fac-similar de seu artigo 'A mulher é uma força ativa na sociedade', publicado no nº 9 da revista $A$ Mensageira, em 1898).

A Mensageira: uma revista de mulheres escritoras na modernização brasileira. Dissertação de mestrado, Campinas, IFCH-Unicamp (mimeo.), 1999. Análise do conteúdo da revista mantida por Prisciliana Duarte na São Paulo do final do século XIX sob a perspectiva da teoria sociológica e da história do pensamento, enumerando-se diversas menções a Marie Rennotte, especialmente nas pp. 204 e 557-9.

Sonetos brasileiros.

2를. ed., Rio de Janeiro, F. Briguiet, 1916.

Os pioneiros americanos no Brasil: educadores, sacerdotes, covos e reis. Trad. do inglês por Olívia Krähenbühl. São Paulo, Livraria Pioneira Editora, 1972. Histórico pormenorizado do movimento migratório dos Estados Unidos para o Brasil no imediato pós-guerra de Secessão (1861-65); confirma as presenças das famílias Ellis e MacIntyre nesse êxodo (pp. 106 e 113-4); no oitavo e último capítulo, 'Canaã' (pp. 157-80), estudam-se as conotações religiosas e político-ideológicas do movimento (destacando-se o papel pioneiro de Martha Watts e seu Colégio Piracicabano, nas pp. 168-9); Robert McIntyre e esposa, pais de Pérola Byington, são citados na p. 168.

Os norte-americanos (confederados) do Brasil: identidades no contexto transnacional. Campinas, Centro de Memória-Unicamp, 1997. Obra baseada na dissertação de mestrado desse antropólogo apresentada à Unicamp em 1996. Recapitulando a história da imigração dos sulistas norte-americanos nas décadas de 1860 e 1870 para a região hoje ocupada pelos municípios paulistas de 
Hilsdorf, Maria Lúcia Spedo

Hilsdorf, Maria Lúcia Spedo

Lacaz, Carlos da Silva

Lapouge, Maryvonne e Pisa, Clelia

Leme, Pedro

Luiz Squilacci

Lima, João Francisco de
Americana e de Santa Bárbara d'Oeste (mas que chegou a abranger uma área ainda maior, que englobava Piracicaba, Rio Claro, Limeira, Capivari e Campinas), Gussi reporta-se a estudos de Maria Lúcia Spedo Hilsdorf relativos à importânci estratégica das escolas confessionais protestantes (batistas, metodistas e presbiterianas, principalmente), colocando em evidência o papel desempenhado pelo Colégio Piracicabano (pp. 109-11) e pelas lojas maçônicas aqui fundadas por estadunidenses (pp. 111-3).

'Os anjos vão ao colégio: Rangel Pestana e a educação feminina'. Revista da Biblioteca Mário de Andrade, São Paulo, vol. 53, pp.47-56, jan.-dez. 1995. Especializada em história da educação, esta docente da USP é autora da dissertação de mestrado Escolas americanas de confissão protestante na província de São Paulo: um estudo de suas origens (USP, 1977) e da tese de doutoramento Francisco Rangel Pestana: jornalista, político e educador (USP, 1986), ambas indispensáveis para o entendimento do complexo contexto histórico-político-ideológico em que se insere a criação do Colégio Piracicabano (em 1881) e a atuação pedagógica progressista de um dos mais destacados líderes republicanos, Rangel Pestana (1839-1903), que, ao lado de Prudente de Morais e Joaquim Mursa, integrou o triunvirato responsável pela administração do estado de São Paulo nas primeiras semanas que se seguiram à proclamação da República. O artigo em epígrafe baseia-se no terceiro capítulo da tese de doutoramento da professora, retratando a situação da educação na província paulista dos anos 1870 e 1880 e abordando a participação do professor João Köpke nos projetos idealizados por Rangel Pestana e pela esposa deste, Damiana Quirino Rangel Pestana.

Tempos de escola: fontes para a presença feminina na educação (São Paulo século XIX). São Paulo, Plêiade Editora, 1999. Compilação de dados relativos aos primórdios da educação feminina paulista; traz, entre outros dados, indicações relativas aos primeiros anos de funcionamento do Colégio Piracicabano (pp. 50-2).

Faculdade de Medicina: reminiscências, tradição, memória de minha escola. São Paulo, edição do autor (impressa por C. L. R. Balieiro Editores), 1985. Histórico pormenorizado da implantação do ensino médico na capital paulista, incluindo (p. 12) dados relativos à primeira turma de formandos da faculdade (1913-18).

Brasileiras: voix, écrits du Brésil. Paris, Éditions des femmes, 1977. Coletânea de entrevistas realizadas pelas autoras com mulheres representativas do Brasil contemporâneo, o volume apresenta, entre as pp. 239 e 244, o texto 'Une vieille dame: doctoresse Carlota Pereira de Queiroz', que retrata a médica paulista, já octogenária e aposentada, visitada na residência de suas sobrinhas, entre as quais se encontra a ilustre socióloga Maria Isaura Pereira de Queiroz. Na p. 242, obtemos a confirmação de que sua observação pessoal da atuação da doutora Marie Rennotte, por volta de 1900, foi fator decisivo para a escolha posterior de sua própria carreira profissional.

'A Santa Casa de São Paulo e os conflitos militares de 1924 e 1932'. Suplemento Cultural nº 107 do Jornal da Associação Paulista de Medicina, São Paulo, set. 2000, pp. 1-3. Embora não traga referências diretas à atuação de Marie Rennotte e Carlota Pereira de Queiroz (nas revoluções, respectivamente, de 1924 e 1932), o artigo de Squilacci Leme fornece um retrato vívido da situação enfrentada pela população paulistana em meio àqueles conflitos, tornando-se útil para a contextuação histórico-biográfica de ambas.

Ana Néri: heroína da caridade. São Paulo, Nova Época Editorial, 1977. Esta biografia inclui a transcrição de elogios fúnebres e reportagens relativas ao sepultamento de Ana Néri, no Rio de Janeiro de 1880 (cap. 8, pp. 194-9); no mesmo capítulo, pp. 203-5, documenta-se a inauguração do retrato a óleo da patrona das enfermeiras do Brasil na sede da Cruz Vermelha Brasileira, em 1925, em cerimônia encerrada com um discurso da doutora Marie Rennotte. 
Monteiro, Eduardo Carvalho

Moraes, Irany Novah

Mott, Maria Lúcia de Barros

Neme, Mário A.

Prado, Antônio de Almeida

Reis Filho, Casemiro dos

Rennotte, Marie
Anália Franco: a grande dama da educação brasileira. São Paulo, Editora Eldorado Espírita, 1992. Documentário de reconstituição da atuação de Anália Franco, incluindo, nas pp. 138 e 140, menções nominais a Marie Rennotte.

'Alma acadêmica'. Suplemento Cultural no 108 do Jornal da Associação Paulista de Medicina, São Paulo, p. 2, nov. 2000. Histórico da instituição da Sociedade de Medicina e Cirurgia de São Paulo (1895), rebatizada Academia de Medicina de São Paulo em 1953. Faz o arrolamento dos médicos então radicados na cidade, responsáveis pela eleição de Pereira Barreto para a presidência da sociedade em fevereiro de 1895 , e, poucos meses depois, pela admissão da doutora Rennotte.

'Madame Durocher, modista e parteira'. Estudos Feministas, Rio de Janeiro, vol. 2, no 3, $1^{\circ}$ semestre 1994, pp. 101-16. No artigo, a historiadora delineia a biografia da bem-sucedida imigrante francesa Maria Josefina Durocher (1809-93), admitida na Academia Imperial de Medicina em 1871; primeira mulher a diplomar-se parteira pela Faculdade de Medicina do Rio de Janeiro, madame Durocher teria se antecipado à atuação das primeiras médicas obstetras do Brasil (tanto na forma de se trajar como em sua maneira direta de intervir na sociedade com propostas de cunho filantrópico). O assunto já havia sido abordado por essa mesma autora no livro Submissão e resistência: a mulher na luta contra a escravidão (São Paulo, Editora Contexto, 1988), em que era analisado (pp. 68-70) o projeto abolicionista elaborado pela Durocher em 1871, modalidade de intervenção que a tornava precursora imediata do ativismo pregado por Marie Rennotte nas duas décadas seguintes. Partindo desse estudo de caso, Barros Mott insere posteriormente suas pesquisas em um quadro mais abrangente, na tese de doutoramento Partos, parteiras e parturientes: madame Durocher e sua época (USP, 1998).

Piracicaba: documentário. Piracicaba, João M. Fonseca, 1936. Na seção educacional deste documentário, incluem-se histórico relativo ao Colégio Piracicabano (pp. 199-200), com a reprodução textual de declarações de Prudente de Morais a seu respeito, e uma descrição do Colégio de Nossa Senhora da Assunção (pp. 202-4).

Escolas de ontem e de hoje: reminiscências e evocações. São Paulo, Anhambi Editora, 1961. Neste volume de memórias escolares do professor de clínica médica Antônio de Almeida Prado (1889-1965), formado no Rio em 1912, docente da nova Faculdade de Medicina de São Paulo (instalada no ano seguinte) desde 1916, reproduz-se, nas pp. 148 e 149, uma fotografia dos alunos da primeira turma desta faculdade, graduada em 1918; entre eles encontram-se as duas primeiras médicas diplomadas em território paulista, Délia Ferraz e Odete Nora.

A educação e a ilusão liberal: origens do ensino público paulista. $2^{2}$ ed., Campinas, Autores Associados, 1995. Obra especialmente útil para o estudo do contexto político-ideológico em que se dá a reforma do ensino público no âmbito paulista, ao longo dos anos 1890, com destaque para o papel desempenhado por Rangel Pestana (pp. 42-4), pelo professor João Köpke (pp. 47-8) e pelos médicos Caetano de Campos (pp. 48-9 e 51-87) e Cesário Mota (pp. 103-14).

Influência da educação da mulher sobre a medicina social. Tese de doutoramento em medicina, apresentada à Faculdade de Medicina e de Farmácia do Rio de Janeiro, 'a fim de poder exercer a sua profissão na República dos Estados Unidos do Brasil'. Rio de Janeiro, Typographia Aldina, 1895. Um dos raros exemplares dessa dissertação, originalmente endereçado a Prudente de Morais (com dedicatória autógrafa da autora), encontra-se no Museu Republicano de Itu, com cópia no Museu do Ipiranga. Abrindo-se a obra com a dedicatória às amigas Martha $\mathrm{H}$. Watts e Ana Maria de Morais Burchard, compõe-se ela do corpo da tese (argumentação apresentada em três partes, da 
Ribeiro, Arilda Inês Miranda

Rodrigues, Leda Maria Pereira (madre Maria Ângela)

Schumaher, Schuma e Brazil, Érico Vital (org.)

Silva, Alberto

Wright, Marie Robinson p. 7 à p. 29), de uma série de proposições doutrinárias ("Três sobre cada uma das cadeiras da Faculdade", páginas seguintes até p. 44), mais uma última página, de aforismos latinos (p. 45).

A educação feminina durante o século XIX: o Colégio Florence de Campinas (1863-1889). Campinas, Centro de Memória-Unicamp, 1996. Estudo monográfico derivado da dissertação de mestrado (Unicamp, 1987) desta educadora relativo a um dos mais importantes colégios femininos particulares do interior paulista no período imperial. Inclui observações relativas a cada um dos professores da escola, sendo de particular interesse (nas pp. 64-73 e 99104) a caracterização da atuação do professor João Köpke, que, lecionando em dois diferentes colégios de Campinas no início dos anos 1880 (no Culto à Ciência e nessa escola feminina de Carolina Florence), representou papel idêntico àquele desempenhado coetaneamente pela mestra Marie Rennotte no Colégio Piracicabano; fluminense de Petrópolis, filho do célebre educador português Henrique Köpke, João Köpke (1853-1926) adota, no ensino de ciências naturais, referencial ideológico e metodológico avançado, antípoda da ausência de conteúdos concretos ou de finalidades práticas que caracterizava o ensino ministrado por religiosas como as irmãs de São José de Chambéry, do ituano Colégio do Patrocínio (fundado em 1859).

A instrução feminina em São Paulo: subsídios para sua história até a proclamação da República. São Paulo, Escolas Profissionais Salesianas, 1962. As inovações introduzidas no ensino particular feminino paulista durante o último quartel do século XIX são descritas no cap. IX deste livro (pp. 163-94), no qual salientam-se as contribuições de Rangel Pestana e sua esposa Damiana Quirino (pp. 187-8), assim como o trabalho pioneiro de Martha Watts e Marie Rennotte na Piracicaba dos anos 1880 (pp. 192-4).

Dicionário mulheres do Brasil: de 1500 até a atualidade. Rio de Janeiro, Jorge Zahar Editor, 2000. Entre muitos outros verbetes biográficos de interesse (acompanhados das respectivas fontes bibliográficas), traz informações detalhadas a respeito de Carlota Pereira de Queiroz (pp. 129-30) e Viridiana Prado (pp. 520-1).

A primeira médica do Brasil. Rio de Janeiro, Irmãos Pongetti Editores, 1954. Biografia da primeira médica formada no Brasil, Rita Lobato Velho Lopes, acrescida de informações a respeito do exercício feminino da profissão desde o século XVIII. O apêndice das pp. 215-33 fornece relação nominal de todas as médicas que se diplomaram ou que revalidaram seus diplomas na Faculdade de Medicina da Bahia, de 1887 até 1951.

The new Brazil. Filadélfia, George Harris \& Son, 1901

\section{PERIÓDICOS DE ÉPOCA}

Almanach Litterario de São Paulo

(São Paulo, 1876-85)
Abrangendo a publicação de oito anuários, esta série de almanaques editada por José Maria Lisboa mostra-se particularmente útil para o estudo da evolução dos conceitos educacionais no final do Império, em um período em que a província passava por acelerada modernização. Destaque-se, no Almanaque para o ano de 1877, pp. 180-1, o detalhado anúncio do "colégio para meninas em São Paulo dirigido por Francisco Rangel Pestana e dona Damiana Quirino Rangel Pestana". O Almanaque para o ano de 1884 traz, nas pp. 209-11, uma incisiva declaração de princípios pedagógicos embutida na matéria 'A diretoria do Culto à Ciência no biênio de 1880-1882', de autoria do professor João Köpke; uma detalhada biografia de Köpke (pp. 225-9) assinada por Rangel Pestana; um artigo em que Damiana Pestana expõe (apoiada em citação spenceriana) suas próprias idéias a respeito da educação infantil (pp. 235-8) e um texto extraído da Astronomie populaire de Camille Flammarion, traduzido 
MARIE RENNOTTE, PEDAGOGA E MÉDICA...

A Mensageira

(São Paulo, 1897-1900)

Revista do Instituto Histórico e Geográfico de São Paulo

(São Paulo, 1937-44)

O Estado de S. Paulo (São Paulo, 1942) do francês por Ana Maria de Morais Barros em 'Piracicaba, julho de 1883' (pp. 219-24). O último anuário da série, Almanaque para o ano de 1885, inclui duas novas matérias assinadas por Ana Maria de Morais Barros: a primeira delas (pp. 155-6) é identificada como 'composição de uma aluna do Colégio Piracicabano, lida nos exames públicos em dezembro de 1882'; a segunda (pp. 233-6) corresponde a uma crônica de elaboração mais recente ('Piracicaba, 11 de agosto de 1884'); cabe notar que essa moça, filha primogênita de Manuel de Morais Barros e sobrinha de Prudente de Morais, ex-aluna de Marie Rennotte, será posteriormente saudada pela imprensa paulistana (depois de casada com o rico empresário alemão Hermann Burchard e de adotar o nome de Ana Maria de Morais Burchard) como uma das mais relevantes beneméritas da capital, de decisiva atuação na fundação da Maternidade de São Paulo pelo doutor Bráulio Gomes (1894).

Nesta 'revista literária dedicada à mulher brasileira', dirigida por Prisciliana Duarte de Almeida (que doou ao IHGSP uma coleção completa, abrangendo 36 números distribuídos em dois volumes, reeditados sob forma fac-similar pela Imprensa Oficial do Estado de São Paulo em 1987), Marie Rennotte é mencionada nos noticiários do $\mathrm{n}^{\mathrm{o}} 1$ (de 15.10.1897), pp. 15-6 do vol. I e do no 25 (de 15.2.1899), p. 23 do vol. II. O no 9 (de 15.2.1898), pp. 141-2 do vol. I, traz um conciso ensaio de autoria da médica, 'A mulher é uma força ativa na sociedade'.

Editada desde 1895, mas com periodicidade irregular, a revista traz referências sumárias à atuação da sócia Marie Rennotte nos volumes XXXIII a XLIII, publicados no período de 1937 a 1944. Vol. XXXIII (1937): nas pp. 421-2, as atas das sessões datadas de 25.1 e 6.2 .1922 antecipam e depois registram sua conferência em homenagem à princesa Isabel ('Uma heroína brasileira'); na p. 423, a ata da sessão extraordinária de 13.2.1922 refere-se ao aparelho de projeção doado à instituição pela médica; na p. 442, descreve-se a conferência relativa a Ana Néri proferida por Rennotte em 5.3.1923. Vol. XXXIV (1938): na p. 768, a ata da sessão datada de 5.3 .1938 registra o voto de congratulações remetido ao interventor federal paulista pela concessão de pensão vitalícia à doutora Rennotte. Vol. XXXV (1938): nas pp. 357-8, comenta-se (ata correspondente à sessão datada de 21.10.1929) o adiamento de uma nova conferência de Marie Rennotte, 'A mulher brasileira na história', que será apresentada a seguir, ainda nessa mesma semana, em 25.10.1929. Vol. XXXVIII (1940): nas pp. 283-4 (ata da sessão de 25.10.1935), transcrevem-se referências às deficiências visual e auditiva de Rennotte, observadas em sua visita ao instituto em 8.10.1935. Vol. XLIII (1944): na p. 365, Marie Rennotte já está incluída na relação de sócios falecidos em 1942; na p. 382, a ata da sessão datada de 5.2.1943 refere-se ao elogio fúnebre da médica proferido pelo amigo e consócio Félix Soares de Melo.

Nos últimos quarenta dias de 1942, o jornal publicou uma seqüência de três elogios fúnebres. O primeiro deles, 'Dra. Maria Rennotte' (edição nº 22.458, do domingo dia 22.11.1942, p. 3) não é assinado, praticamente se limitando a lembrar aos leitores quem tinha sido aquela idosa senhora falecida e sepultada na véspera. O segundo, de autoria de Mário Guastini, 'Uma grande benemérita' (edição no 22.459, da terça-feira dia 24.11.1942, p. 3) já se refere à sua atuação como médica e filantropa, chamando-a 'perdulária da bondade', pela generosidade que acabara reduzindo-a à penúria. A seqüência fecha-se com a transcrição, na edição no 22.489 (de 30.12.1942, p. 6), sob a epígrafe 'Cruz Vermelha Brasileira', de um discurso no qual Ana Maria de Revoredo recapitulava a biografia de Rennotte. Esta última matéria é acompanhada de um pequeno clichê reproduzindo aquela que deve ter sido a última fotografia da doutora. 